Journal of

Molecular Microbiology

and Biotechnology
J Mol Microbiol Biotechnol 2007;12:165-179

DOI: $10.1159 / 000099639$

\title{
Large-Scale Comparative Genomic Analyses of Cytoplasmic Membrane Transport Systems in Prokaryotes
}

\section{Qinghu Ren Ian T. Paulsen}

The Institute for Genomic Research, Rockville, Md., USA

\author{
Key Words \\ Membrane transporter • Prokaryotic genomes • \\ Eubacteria $\cdot$ Archaea $\cdot$ Phylogenetic profiling
}

\begin{abstract}
The recent advancements in genome sequencing make it possible for the comparative analyses of essential cellular processes like transport in organisms across the three domains of life. Membrane transporters play crucial roles in fundamental cellular processes and functions in prokaryotic systems. Between 3 and $16 \%$ of open reading frames in prokaryotic genomes were predicted to encode membrane transport proteins, emphasizing the importance of transporters in their lifestyles. Hierarchical clustering of phylogenetic profiles of transporter families, which are derived from the presence or absence of a certain transporter family, showed distinct clustering patterns for obligate intracellular organisms, plant/soil-associated microbes and autotrophs. Obligate intracellular organisms possess the fewest types and number of transporters presumably due to their relatively stable living environment, while plant/soil-associated organisms generally encode the largest variety and number of transporters. A group of autotrophs are clustered together largely due to their absence of transporters for carbohydrate and organic nutrients and the presence of transporters for inorganic nutrients. Inside of each group, organisms are further clustered by their phylogenetic properties. These
\end{abstract}

findings strongly suggest the correlation of transporter profiles to both evolutionary history and the overall physiology and lifestyles of the organisms.

Copyright $\odot 2007$ S. Karger AG, Basel

\section{Introduction}

Membrane transport systems are vital to every living organism. Transporters function in the acquisition of organic nutrients, maintenance of ion homeostasis, extrusion of toxic and waste compounds, environmental sensing and cell communication, and other important cellular functions [Saier, 1999], therefore playing essential roles in life-endowing processes like metabolism, communication, and reproduction. There has also been increasing evidence suggesting the relevance of the composition of membrane transport systems to the general physiology and lifestyles of the organisms [Paulsen et al., 1998, 2000; Ren and Paulsen, 2005].

Various transport systems differ in their putative membrane topology, energy coupling mechanisms and substrate specificities [Saier, 2000]. The most commonly utilized energy sources to drive transport are adenosine triphosphate (ATP), phosphoenolpyruvate, or chemiosmotic energy in the form of sodium ion or proton electrochemical gradients. Primary active transporters couple the transport process to a primary source of energy

\section{KARGER \\ Fax +41613061234 \\ E-Mail karger@karger.ch}

www.karger.com (c) 2007 S. Karger AG, Basel

$1464-1801 / 07 / 0124-0165 \$ 23.50 / 0$

Accessible online at:

www.karger.com $/ \mathrm{mmb}$
Ian T. Paulsen

The Institute for Genomic Research

9712 Medical Center Dr.

Rockville, MD 20850 (USA)

Tel. +1 301795 7531, Fax +1 301838 0208, E-Mail ipaulsen@tigr.org 
(ATP hydrolysis), for example, the MalKGFE maltose transporter from Escherichia coli [Bohm et al., 2002; Boos and Shuman, 1998]. Secondary transporters utilize an ion or solute electrochemical gradient, such as the proton/sodium motive force, to drive the transport process, e.g. E. coli LacY lactose permease [Abramson et al., 2003; Newman et al., 1981; Viitanen et al., 1986]. Group translocators transport and phosphorylate their substrates. $E$. coli MtlA mannitol PTS transporter phosphorylates exogenous mannitol using phosphoenolpyruvate as the phosphoryl donor and energy source and releases the phosphate ester, mannitol-1-P, into the cell cytoplasm [Elferink et al., 1990; Postma et al., 1993]. Compared to other transporter types, channels are unique in that they are energy-independent transporters that transport water, specific types of ions or hydrophilic small molecules down a concentration or electrical gradient with higher rates of transport and lower stereospecificity, e.g. E. coli GlpF glycerol channel [Sweet et al., 1990].

Cytoplasmic membrane transporters typically consist of at least one membrane-localized protein component with multiple transmembrane-spanning $\alpha$-helical segments. This has led to membrane transport systems being difficult to study experimentally. The genomic/bioinformatic analyses provide an attractive alternative to study membrane transporters [Ren et al., 2004]. As of today, over 400 prokaryotic genomes have been sequenced and deposited in the public databases (Gold Genomes Online Database, http://www.genomesonline.org/) [Bernal et al., 2001; Janssen et al., 2005]. These genomes cover a broad range of microbial organisms from different phylogenetic groupings, allowing comparative genomic analyses across a diverse range of organisms and lifestyles. The functional prediction and classification of complete membrane transport systems in these sequenced genomes, as well as the comparative analyses of transporter profiles from related organisms are of great value in understanding organisms' physiology and lifestyles.

In this review, we present a comparative genomic study of prokaryotic membrane transport systems from 201 sequenced genomes, with the focus on their relationship to their overall physiology and lifestyles.

\section{Comparative Genomic Analysis of Membrane Transport Systems}

Bioinformatic analyses of 201 species, including 178 eubacteria and 23 archaea (table 1) enabled us to identify a total of 53,669 transport proteins. Based on se- quence similarities and phylogenetic analyses, these transport proteins could be categorized into 94 families, including 5 families of primary transporters, 70 families of secondary transporters, 11 channel protein families, 2 phosphotransferase systems, and 6 unclassified families. Some of these families are very large superfamilies with numerous members, such as the ATP-binding cassette superfamily $(\mathrm{ABC})$ and the major facilitator superfamily (MFS), both of which are widely distributed across the eubacterial and archaeal species. Some families, on the contrary, only exist in a very limited phylogenetic spectrum and/or are present in only limited numbers.

The total number of predicted cytoplasmic membrane transport proteins (fig. 1a) and the percentage of transport proteins relative to the total number of open reading frames (ORFs) (fig. 1b) were compared for the 201 prokaryotes (listed by their phylogenetic groupings). Between 3 and $16 \%$ of ORFs in prokaryotic genomes were predicted to encode membrane transport proteins, emphasizing the importance of transporters in the lifestyles of all eubacterial and archaeal species. There is considerable variation on the quantity of transport proteins, even for species within the same phylogenetic group. For example, organisms within the $\alpha$-Proteobacteria exhibit distinct lifestyles and corresponding differences in transporter contents. They include the rhizosphere-dwelling organisms Mesorhizobium loti (884 transport proteins, $12.2 \%$ of ORFs), Bradyrhizobium japonicum (987, 11.9\%) and Sinorhizobium meliloti (827, 13.3\%); the plant pathogen Agrobacterium tumefaciens (824, 15.3\%); the human pathogens Brucella spp. (360379, 11.0-11.9\%); marine Roseobacters, like Silicibacter pomeroyi (571, 13.4\%) and Jannaschia sp. (507, 12.0\%), and obligate intracellular pathogens or endosymbionts such as Rickettsia spp., Wolbachia spp., Anaplasma spp., and Ehrlichia spp. (53-59, 4.5-7.0\%). Across all phyla, obligate endosymbionts and intracellular pathogens generally seem to possess the most limited repertoire of membrane transporters.

Organisms with the lowest percent of ORFs encoding transport proteins include Pirellula sp. (225, 3.1\%), a marine aerobic heterotrophic planctomycete; Leptospira interrogans (147, 3.1\%), a parasitic pathogenic spirochaete, and several archaeal species, such as Methanococcus jannaschii (68, 3.9\%), Methanopyruskandleri (54, 3.2\%), and Nanoarchaeum equitans (17, 3.0\%). One of the contributing factors could be the very limited experimental characterization of species in these phylogenetic groupings, which serves the base for bioinformatic predictions. Pre- 
Table 1. Organisms used in this study and their transport proteins

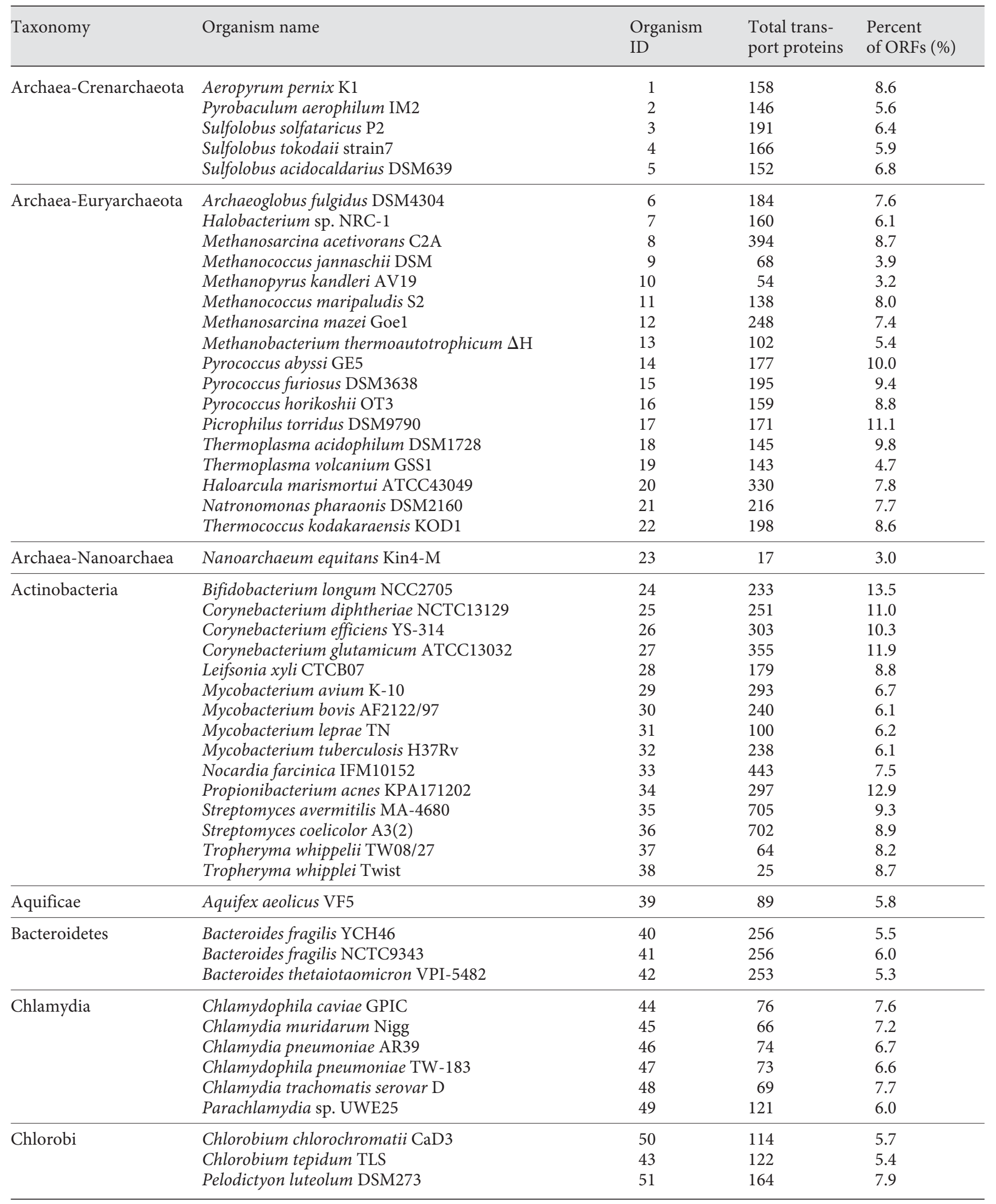


Table 1 (continued)

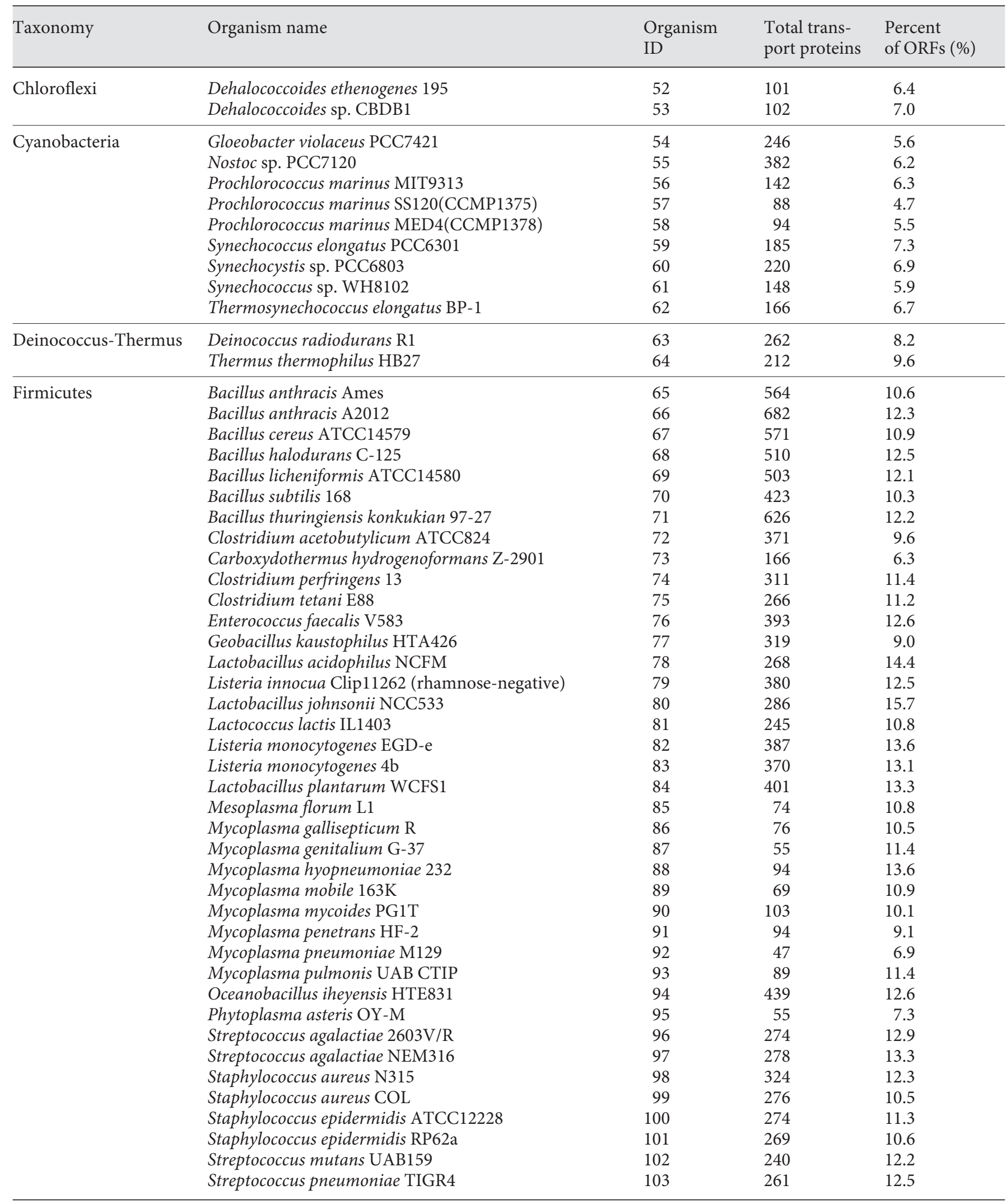


Table 1 (continued)

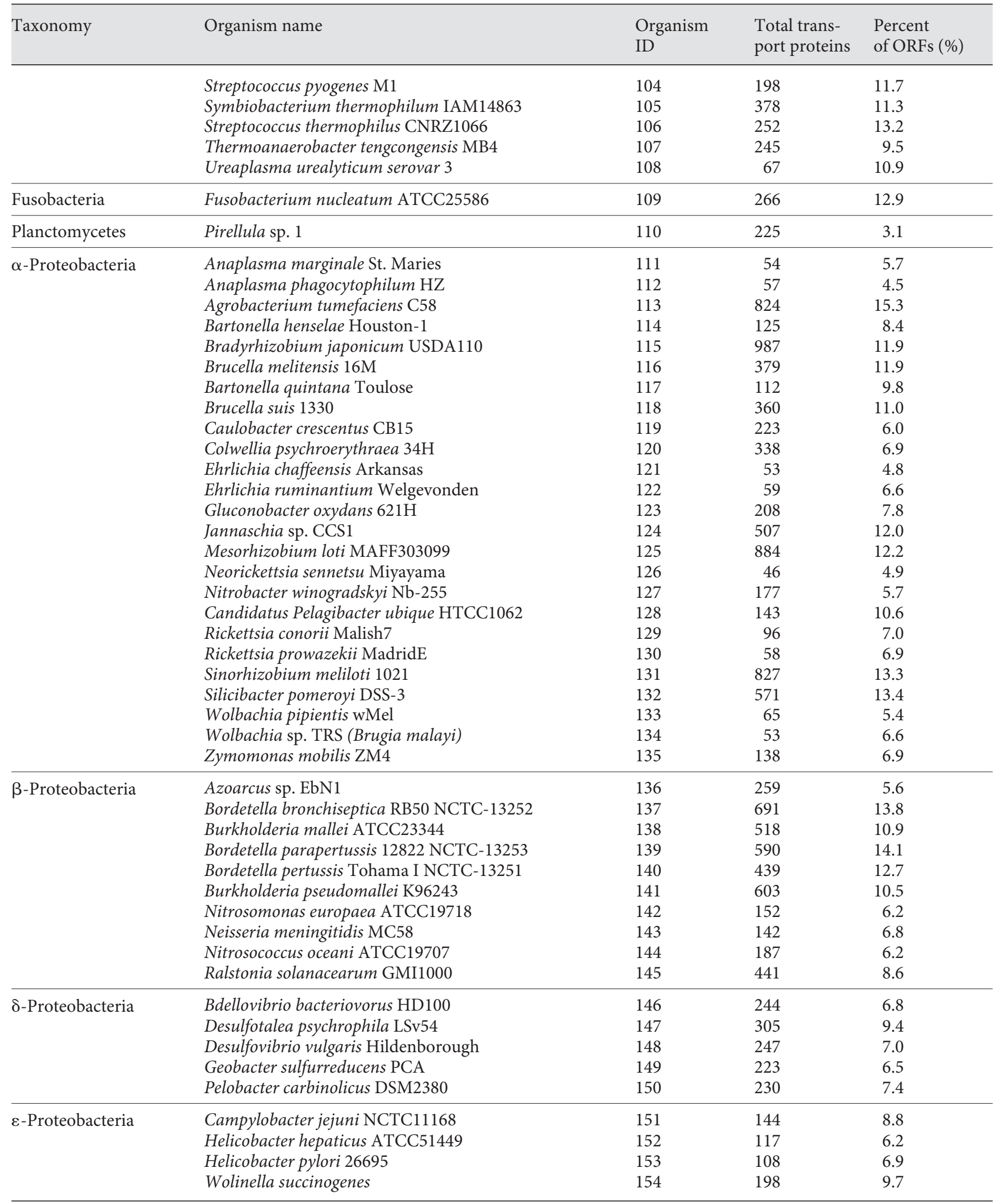


Table 1 (continued)

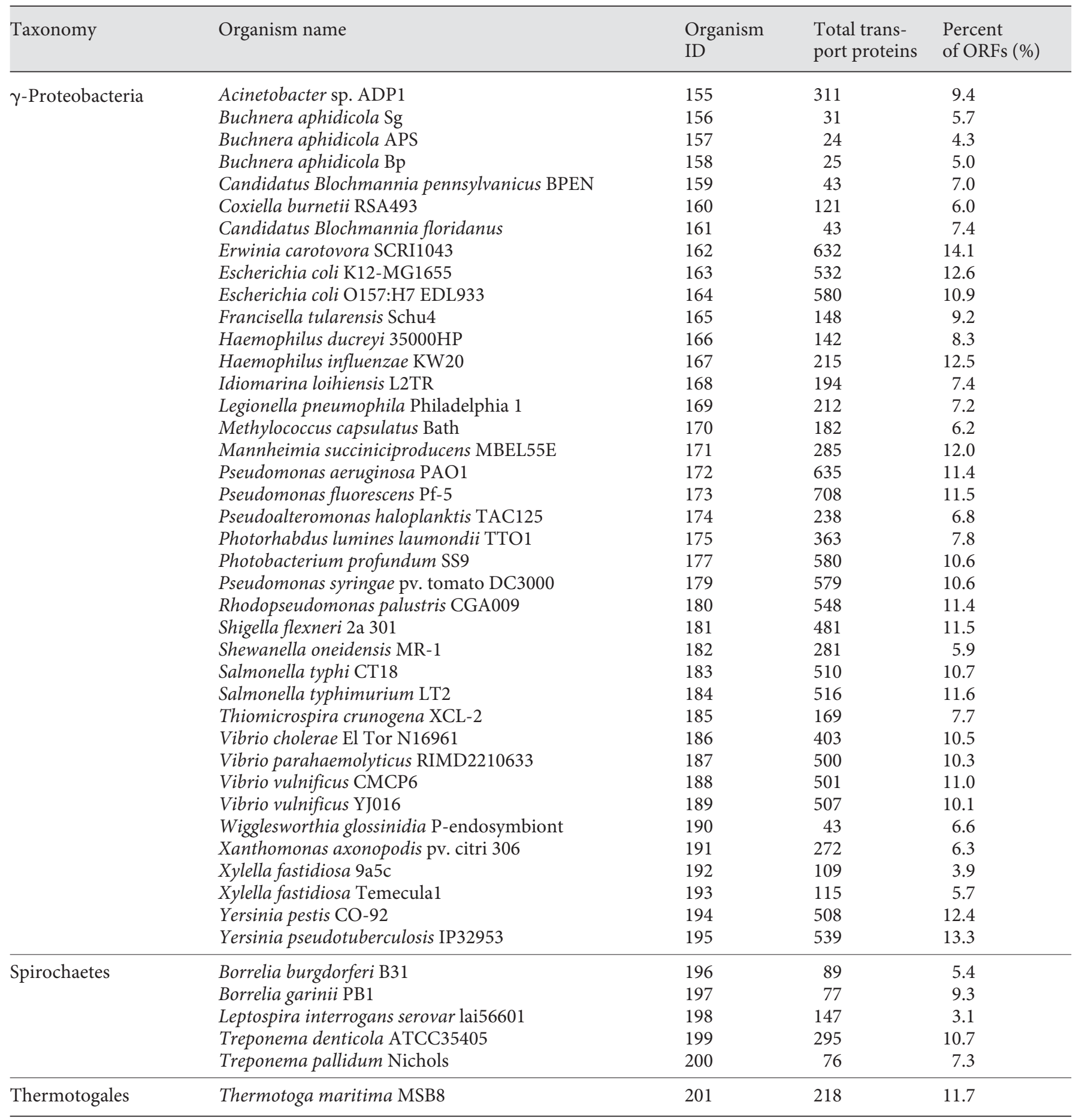

Fig. 1. The overall numbers of recognized transport proteins. Organisms from distinct phylogenetic groups are labeled with different colors. The obligate intracellular parasites/pathogens are marked with red stars. a Total number of transport proteins in 201 prokaryotes. $\mathbf{b}$ Transport proteins as the percentage of total ORFs. c Distribution of sodium-dependent amino acid/solute symporters across six families: NSS = light blue; AGCS = orange; SSS = salmon; DASS = lime; glutamate:sodium symporter family $(\mathrm{ESS})=$ pink; LIVCS $=$ dark blue. 

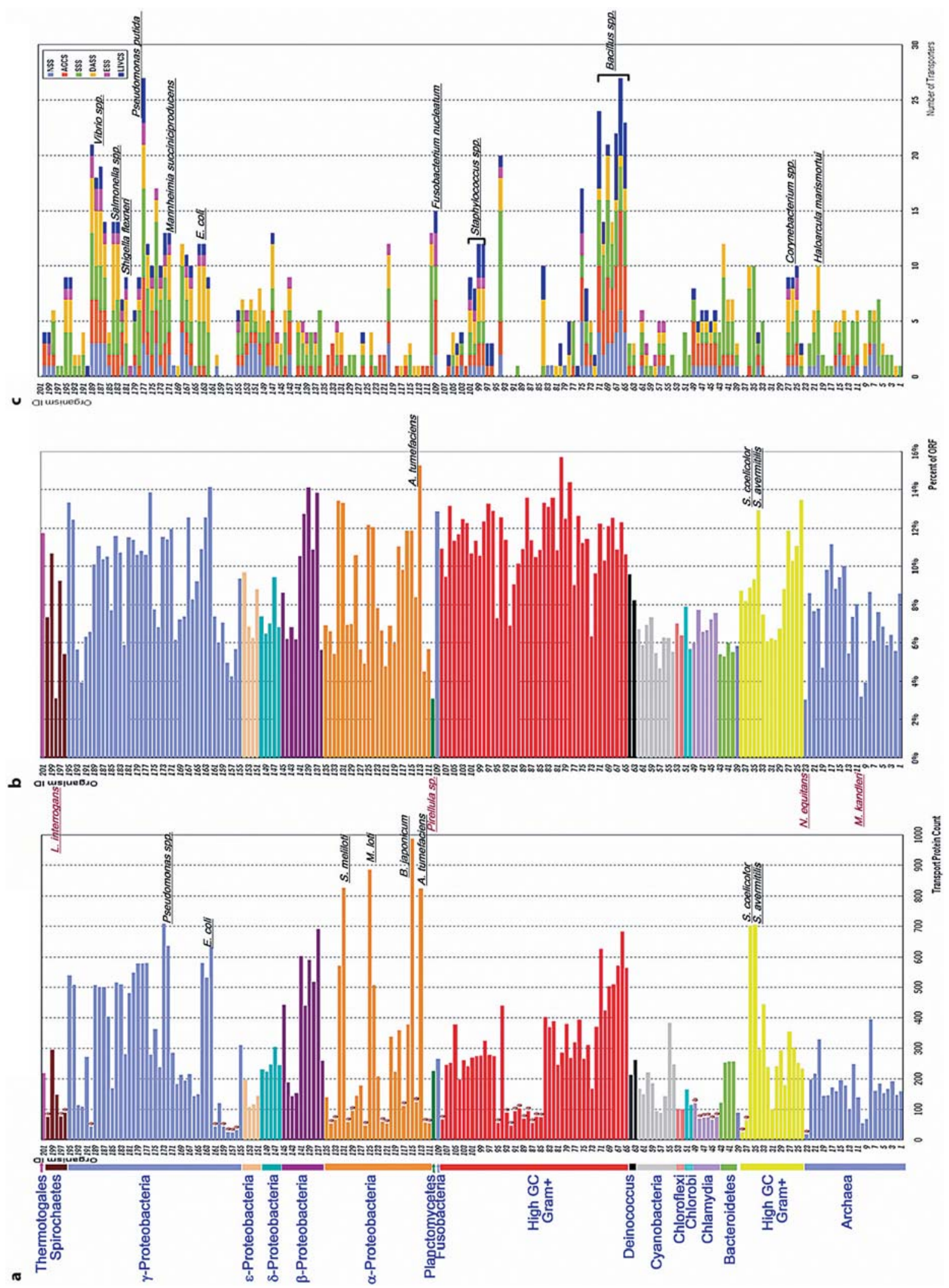
vious studies show that archaeal species have much higher percentages of membrane proteins assigned to the role category of 'hypothetical proteins' than eubacterial species [Ren and Paulsen, 2005]. Some of these 'hypothetical proteins' could function in novel transport processes.

Although obligate intracellular organisms and small free-living parasites overall present the fewest transport proteins, they still devote a relatively high percentage of ORFs towards transport functions. For example, Mycoplasma spp. have over $10 \%$ of their ORFs encoding transport proteins. Transport proteins consist of average $7.7 \%$ of ORFs in 38 obligate intracellular and small free-living parasites, compared to an average of $8.9 \%$ in all organisms. Although most of these organisms appear to have undergone substantial reductive evolution, it seems that they have not preferentially lost or retained transporter genes as a consequence of their adaptation to intracellular lifestyles. Most of these organisms have various defective biosynthesis pathways, and have to uptake essential nutrients and intermediate metabolites from their host. Detailed examinations of transporter profiles show that these organisms have different degrees of reduction as to the types of transporters and categories of substrate. Compared to other prokaryotes, obligate intracellular organisms exhibit greater degree of reduction in efflux pumps and transporters for ions and small inorganic compounds. However, they appear to have retained a significant percentage of importers in the genome for essential nutrients and intermediate metabolites.

\section{Phylogenetic Profiling as a Tool for Investigating Membrane Transport Content}

The phylogenetic profile of a gene is a pattern representing the presence or absence of homologues in a set of fully sequenced genomes. Genes with similar phylogenetic profiles, as assessed by Pearson correlation coefficient, likely could function together in a pathway or are part of a complex because they are likely to evolve in a correlated fashion and tend to be either preserved or eliminated during evolution [Pellegrini et al., 1999; Pellegrini, 2001]. Phylogenetic profiling has many applications in genomics studies, such as detection of conserved core genes, lineage-specific gene family expansions [Vandepoele and Van de Peer, 2005], subcellular localization of proteins [Marcotte et al., 2000], prediction of physical and functional interactions and deduction of the functions of genes that have no well-characterized homologues [Levesque et al., 2003; Wu et al., 2005].
Previously we employed a novel application of phylogenetic profiling to investigate the presence or absence of transporter protein families across 141 sequenced prokaryotes and eukaryotes [Ren and Paulsen, 2005]. Compared to other studies, we used protein families rather than individual proteins as the unit of comparison. The phylogenetic profiling of transporter families provided interesting insights into the distribution of transporters across a broad range of organisms. Organisms from various phylogenetic groups which are adapted to similar environmental niches were often found in clusters. Inside each cluster, organisms were further grouped together by their phylogenetic history. Given that the profiling approach solely utilizes presence/absence of a transporter family and does not use sequence similarity directly, these findings suggest that the types of transporters utilized by an organism are related both to their physiology and to their evolutionary history.

The fast growing number of completely sequenced genomes enabled us to enhance the resolution of this phylogenetic profiling analysis. With the data on membrane transport systems from 201 fully sequenced prokaryotes, we were able to construct more detailed phylogenetic profiles for each transporter family (fig. 2). In line with our previous observations, hierarchical clustering of phylogenetic profiles showed a strong correlation between the observed clustering pattern and phylogeny, with distinct phylogenetic groupings of eubacteria and archaea clearly separated into different clusters, such as high GC Gram+, low GC Gram+, Proteobacteria, Chlamydia, Cyanobacteria, etc. (fig. 2, 3). Additionally, the clustering patterns are influenced by the lifestyle of organisms. The obligate intracellular pathogens/symbionts, the soil/plant-associated microbes and a collection of autotrophs are separated into distinct super-clusters (fig. 2, 3). These findings demonstrate that phylogenetic profiling is a viable and potent approach to the bioinformatic study of membrane transporters.

The obligate intracellular pathogens/symbionts cluster includes a group of phylogenetically diverse organisms (fig. 3b), including Chlamydia (pathogens); $\gamma$-Proteobacteria like Buchnera spp., Wigglesworthia glossinidia and Candidatus Blochmannia spp. (endosymbionts); $\alpha$-Proteobacteria such as Wolbachia spp. (endosymbionts) and Anaplasma spp., Ehrlichia spp., Rickettsia spp., Neorickettsia sennetsu, Bartonella spp. (pathogens); low GC Gram+-like organisms Mycoplasma spp., Ureaplasma urealyticum, Phytoplasma asteris and Tropheryma whipplei (pathogens); Spirochetes like Treponema pallidum, Borrelia spp. (pathogens); and an archaeal endo- 
Fig. 2. Phylogenetic profiling of transporter families. Phylogenetic profiles were created for each transporter family. Each profile is a string with 201 entries (number of organisms analyzed). If a given family is present in an organism, the value ' 1 ' is assigned at this position (red color). If not, ' 0 ' is assigned (black color). Organisms and transporter families were clustered according to the similarity of their phylogenetic profiles.

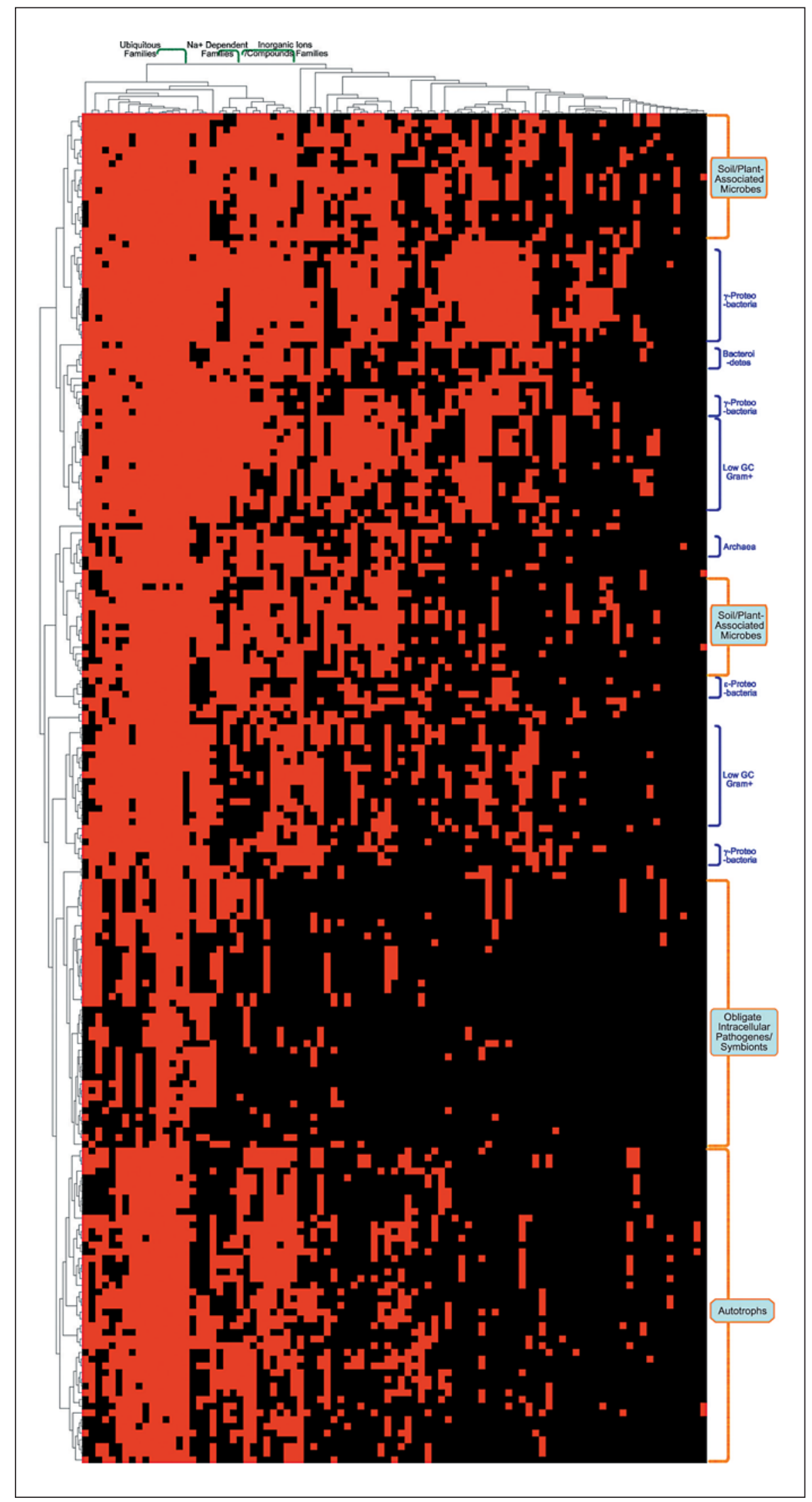

J Mol Microbiol Biotechnol 2007;12:165-179 
Fig. 3. Detailed view of three clusters of organisms generated by hierarchical clustering of their phylogenetic profiles of transporter families: soil/plant-associated microbes (a), obligate intracellular pathogens/symbionts (b) and autotrophs (c).
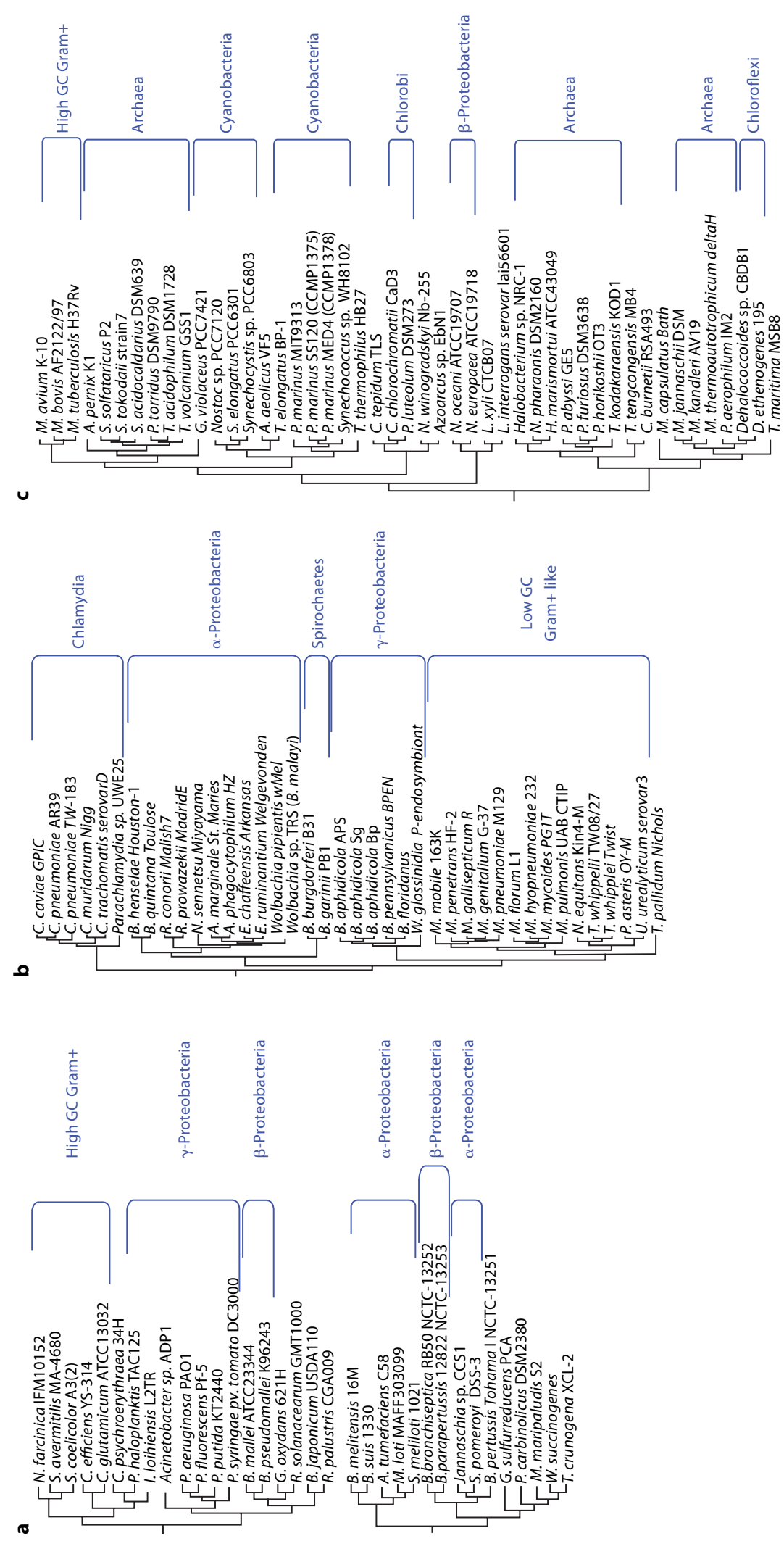
symbiont, $N$. equitans. Organisms in this cluster are mostly obligate intracellular organisms, with one or two exceptions, e.g. Bartonella spp. that are facultative intracellular pathogens. The transport needs for these obligate intracellular organisms are probably more specialized than those of environmental organisms due to the less dynamic nature of their intracellular environments. This may have allowed them to shed, for example, transporters for alternative nitrogen/carbon sources, drug/toxic metabolite efflux, osmoregulation, and ion homeostasis. The residual transport systems conserved in these obligate intracellular organisms probably belong to the core essential genes required for the acquisition of key nutrients and metabolic intermediates. For example, in Rickettsia species, genes coding for proteins functioning in glycolysis and the biosynthesis of S-adenosylmethionine and nucleotides are absent [Andersson and Andersson, 1999; Andersson et al., 1998; Dunning Hotopp et al., 2006; Ogata et al., 2001]. They completely rely on the hosts for these small molecules. As expected, transporter systems for the uptake of nucleoside monophosphates (ATP:ADP antiporter family), S-adenosylmethionine (drug/metabolite transporter superfamily) [Tucker et al., 2003], and glycerol-3-phosphate (MFS family) have been identified [Dunning Hotopp et al., 2006]. The essential glutamate transporters in two obligate endosymbionts Candidatus Blochmannia floridanus and W. glossinidia provides another example: The GltP glutamate:proton symporter (DAACS family) is encoded in B. floridanus [Tolner et al., 1995], while the GltJKL ABC transporter is expressed in W. glossinidia [Linton and Higgins, 1998]. Both of these organisms have a truncated TCA cycle which begins with $\alpha$-ketoglutarate and ends with oxaloacetate [Zientz et al., 2004]. Their TCA cycle could be closed by the transamination of the imported glutamate to aspartate, catalyzed by an aspartate aminotransferase which uses oxaloacetate as a cosubstrate and produces $\alpha$ ketoglutarate. Compared to the plant/soil-associated microbes, obligate intracellular organisms show a higher degree of variation in terms of energy coupling mechanism and transport mode. These variations may reflect the unique internal environment inside the host cells. All these observations illustrate how adaptation of an organism to certain living conditions leads to changes in its transporter repertoire and at the same time determine the set of transporters that the organism cannot afford to lose.

The soil/plant-associated microbes form two clusters, including organisms from various phylogenetic groups (fig. 3a). The first cluster includes Actinobacteria (Cory-

Comparative Analyses of Membrane

Transport Systems in 201 Prokaryotes nebacterium spp., Nocardia farcinica and Streptomyces spp.), $\gamma$-Proteobacteria (Actinobacter sp., Idiomarina loihiensis, Pseudomonas spp., Pseudoalteromonas haloplanktis and Rhodopseudomonas palustris), and $\beta$-Proteobacteria (Burkholderia and Ralstonia). The second one includes mainly $\alpha$-Proteobacteria (A. tumefaciens, Brucella spp., Jannaschiasp., M. loti, S. pomeroyi and S. meliloti), $\beta$-Proteobacteria (Bordetella spp.), $\delta$-Proteobacteria (Geobacter sulfurreducens and Pelobacter carbinolicus), and $\varepsilon$-Proteobacteria (Wolinella succinogenes). This is in contrast to our previous analysis [Ren and Paulsen, 2005] in which these organisms formed one coherent cluster with two major branches comparable to the two clusters shown here. The first cluster is close to other $\gamma$-Proteobacteria like E. coli which has the highest diversity of transporter families among all prokaryotic organisms, partly due to the extensive experimental studies carried on this model organism. The second cluster is close to other $\delta$-Proteobacteria and $\varepsilon$-Proteobacteria. Therefore, the respective phylogenetic relationships of these two clusters override the linkage by the influence of living environment on transporter contents as observed previously. One of the possible reasons causing the disparity could be the great expansion of $\gamma$-Proteobacteria species used in this study which may have exerted a stronger influence on the clustering. All of the organisms in these two clusters possess a robust collection of transporter systems. The similarity of phylogenetic profiles of organisms in these clusters probably reflects the versatility of these organisms and their exposure to a wide range of different substrates in their natural environment. The majority of species in this cluster can be free-living in the soil and some are capable of living in a diverse range of environments. They generally share a broad range of transport capabilities for plant-derived compounds specifically and for organic nutrients in general. Interestingly, some of the human facultative pathogens, such as Bordetella and Brucella, are also grouped in this cluster. These pathogens have close relatives that are soil or plantassociated environmental organisms [Parkhill et al., 2003; Paulsen et al., 2002], so their transport capabilities probably reflect a combination of their evolutionary heritage, original environmental niche and their current transport needs.

The third significant cluster of phylogenetic profiling of transporter families consists primarily of autotrophs (fig. 3c). This cluster was not found in our previous analysis [Ren and Paulsen, 2005] because of the lack of data on autotrophs. Obligate autotrophs obtain energy exclusively by the oxidation of inorganic substrates and use 
$\mathrm{CO}_{2}$ as the only resource of carbon [Kowalchuk and Stephen, 2001], such as the nitrifying bacteria Nitrobacter winogradskyi (oxidizing nitrite ion); Nitrosomonas europaea and Nitrosococcus oceani (oxidizing ammonium ion). Facultative autotrophs obtain some part of their energy from oxidation of iron, sulfur, hydrogen, nitrogen, and carbon monoxide. These include green sulfur bacteria (Chlorobium spp. and Pelodictyon luteolum), green nonsulfur bacteria (Dehalococcoides spp.), both of which are anaerobic photosynthetic bacteria; Cyanobacteria (Prochlorococcus spp., Synechococcus spp., Synechocystis sp., Nostoc sp., Gloeobacter violaceus and Thermosynechococcus elongates) which are aerobic photosynthetic bacteria; a hydrogen-oxidizing, microaerophilic, obligate chemolithoautotrophs (Aquifex aeolicus); an obligate methanotroph, Methylococcus capsulatus; and a group of autotrophic archaeal species (Aeropyrum pernix, Sulfolobus spp., Picrophilus torridus, Thermoplasma spp., Methanobacterium thermoautotrophicum, M. kandleri, M. jannaschii, Pyrobaculum aerophilum, Pyrococcus spp., Thermococcus kodakaraensis, Natronomonas pharaonis, Haloarcula marismortui, and Halobacterium sp.). In line with their metabolism features, organisms in this cluster generally lack transporters for carbohydrates, amino acids, carboxylates and nucleosides, etc. Instead, they encode a full array of transporters for various cations and anions, ammonium, inorganic phosphate, and sulfate which feed into their autotrophic metabolism. These features distinguish this group of autotrophs from organisms in the plant/soil-associated and intracellular pathogen/endosymbiont clusters. Interestingly, some heterotrophic bacteria were included in this cluster. They generally fall into several categories: Pathogens that are evolved from environmental organisms, like Leifsonia xyli and L. interrogans; organisms with extensive ion transport systems and/or few organic nutrient transporters, like Thermoanaerobacter tengcongensis, Coxiella burnetii and Mycobacterium spp., and a Thermotogales (Thermotoga maritima) with extensive array of archaeal-lineage genes [Nelson et al., 1999], and was found to cluster with the archaeal species in this super-cluster.

Comparison of the transporter profiles of marine microbes shows a close relationship between their transporter profiles and their physiology and ecological niches. The sequenced marine microbes to date can be categorized into three groups according to their metabolism and ecological niche: Cyanobacteria clade (photosynthetic autotrophs); Roseobacter clade (such as Jannaschia sp. and S. pomeroyi) that are metabolically versatile and capable of utilizing diverse organic and inorganic nutrients in the coastal and oceanic planktonic environment [Moran et al., 2004]; and a group of oligotrophic bacteria that are metabolically conservative and more specialized in scavenging organic nutrients in seawater [Button, 1991], such as Oceanobacillus iheyensis, Vibrio vulnificus, I. loihiensis, Pelagibacter ubique and Photobacterium profundum.

Cyanobacteria, which feature few importers for organic nutrients and a more substantial array of transporters for ion and inorganic compounds, belong to the autotroph cluster (fig. 3). Detailed examination of two Cyanobacteria species with different ocean environmental niches shows quite different transporter profiles [Palenik et al., 2006]: the coastal cyanobacterium, $S y$ nechococcus sp. strain CC9311, has a much larger capacity to transport, store, utilize or export metals, especially iron and copper than an open ocean oligotrophic strain, Synechococcus sp. strain WH8102, which could be related to its greater capacity to sense and respond to changes in its (coastal) environment. In contrast, WH8102 has systems predicted for the efflux of arsenite and chromate [Palenik et al., 2003] that are not found in CC9311. The Roseobacter clade, however, was clustered with plant/soil-associated clusters (fig. 3 ) due to their abundant and diverse transporters for both organic nutrients (peptides, amino acids, sugars, putrescine and spermidine, taurine, glycine betaine and dimethylsulphoniopropionate, etc.) and inorganic compounds (urea, phosphate, inorganic ions, sulfate, etc.) which enable them to take advantage of transient occurrences of high-nutrient niches within a bulk low-nutrient environment. One of the distinguishing features of Roseobacters are their uncommonly high number of TRAP transporter systems (26 systems for S. pomeroyi and 28 for Jannaschia sp., no other sequenced genome has more), probably reflecting their capability to import carboxylic acids produced in surface waters during photo-oxidation of dissolved organic matters, like glyoxylate and acetate [Moran et al., 2004]. The metabolically conservative marine heterotrophs did not form any distinct grouping and were clustered primarily by their phylogenetic traits. For example, O. iheyensis was clustered with other Bacillus spp.; and V. vulnificus and $P$. profundum were clustered with other Vibrio spp. $P$. ubique represents one of the smallest free-living nonparasitic microorganism [Giovannoni et al., 2005] with 1,354 ORFs, of which 143 encode transport proteins (10.6\%). Compared to obligate intracellular organisms, it encodes a large number of transporters for diverse ni- 
trogenous compounds, such as ammonium, urea, basic amino acids, spermidine, and putrescine. These features clearly exclude it from the obligate intracellular organism cluster.

The clustering of transporter families also show features related to the lifestyles of organisms. The ubiquitous families, like ABC, MFS, P(F)-type ATPase, which are present in virtually every organism we analyzed, are clustered together. A group of sodium ion-dependent transporter families, the neurotransmitter:sodium symporter (NSS), alanine/glycine:cation symporter (AGCS), solute:sodium symporter (SSS), and divalent anion:sodium symporter (DASS) are clustered together. Transporters in these families are all symporters which utilize the sodium ion gradient to transport amino acid, solute, and/or divalent ions to cytoplasm. This clustering may suggest that these families co-occur in a specific set of organisms, presumably those most reliant on sodium ion-driven transport. Figure $1 \mathrm{~d}$ shows the detailed distribution of six sodium ion-dependent amino acid/solute transporter families in the 201 prokaryotic organisms we analyzed. We see considerable variation in the distribution of these families among phylogenetically related species. For example, Mycobacterium spp. and Corynebacterium spp. are closely related Actinobacteria. M. tuberculosis and C. diphtheriae are both pathogens of human respiratory systems. Corynebacterium spp. encode members of all six sodium-dependent transporter families, while Mycobacterium spp. have none. In fact, Mycobacterium spp. were clustered with the autotrophic bacteria as an artifact on our phylogenetic profiling studies (fig. 3c) at least in part due to their lack of sodium-dependent transporters.

In general, environmental organisms such as Bacillus spp. (including Oceanbacillus and Lactobacillus spp.), Colwellia psychroerythraea, Pirellula sp. and Pseudomonas spp. present the highest number of sodium-dependent pumps, while organisms with autotrophic lifestyles encode very few sodium ion-driven transporters, and those they do possess are more likely involved in the uptake of simple compounds such as sulfate rather than amino acids or carboxylates. Some of these autotrophs completely lack this type of transporters, such as Dehalococcoides spp., M. kandleri, N. winogradskyi, and N. europaea. There are a couple of interesting exceptions: H. marismortui, a halophilic microorganism that thrives in extreme saline environments, encodes 10 members of sodium-dependent transporters in NSS, SSS and DASS families, the highest number among all archaeal species studied. Halobacterium sp., another archaeal organism, which, like H. marismortui, proliferates in saturating salt solutions, also has 6 members of such transporters. These probably reflect their adaptation to a high-salt environment. A group of human pathogens encode relatively large numbers of sodium-dependent pumps, including Enterobacteriaceae (such as E. coli, Salmonella, Shigella, Yersinia and Vibrio spp.), Staphylococcus spp., Corynebacterium spp. and Fusobacterium nucleatum, etc. These could also be related to the high-salt environment in human GI tract, oral cavity and respiratory tract. Actually human epithelial cells utilize the same mechanism to uptake nutrients from the GI tract and to regulate the internal homeostasis. Among those organisms with obligate intracellular lifestyles, which need to obtain nutrients like amino acids from their host, the majority do not encode sodium-dependent amino acid transporters. Instead, they typically encode $\mathrm{ABC}$ family amino acid transporter and/or APC family amino acid:proton symporters or amino acid:amino acid antiporters. Chlamydia spp. are the only group of obligate intracellular organisms that show homologues in each of the six sodium-dependent amino acid/solute families.

There is another cluster of families for inorganic ions and small compounds, including potassium and chloride ion channels, ammonium transporter, inorganic phosphate transporter, sulfate permease, and calcium: cation antiporter. Autotrophic eubacterial and archaeal organisms generally utilize transporters in these families for the uptake of inorganic compounds, as well as soil/plant-associated microbes and other environmental organisms. As expected, obligate intracellular pathogens and endosymbionts generally lack this type of transporters.

\section{Conclusion}

The era of complete genome sequencing has opened new horizons in our understanding of complex biological questions. Comparative genomic approaches for the analysis of membrane transport systems have provided us invaluable insights on how microbes adapt to their environment. The observations that organisms with similar lifestyles and/or ecologic niches (obligate intracellular, soil/plant-associated, or autotrophic) display similar phylogenetic profiles despite their phylogenetic differences strongly suggest the influence of their environments on their membrane transport gene complement. 


\section{References}

-Abramson J, Smirnova I, Kasho V, Verner G, Iwata S, Kaback HR: The lactose permease of Escherichia coli: overall structure, the sugarbinding site and the alternating access model for transport. FEBS Lett 2003;555:96101.

-Andersson JO, Andersson SG: Genome degradation is an ongoing process in Rickettsia. Mol Biol Evol 1999; 16:1178-1191.

-Andersson SG, Zomorodipour A, Andersson JO, Sicheritz-Ponten T, Alsmark UC, Podowski RM, Naslund AK, Eriksson AS, Winkler $\mathrm{HH}$, Kurland CG: The genome sequence of Rickettsia prowazekii and the origin of mitochondria. Nature 1998;396:133-140.

- Bernal A, Ear U, Kyrpides N: Genomes OnLine Database (GOLD): a monitor of genome projects world-wide. Nucl Acids Res 2001;29: 126-127.

Bohm A, Diez J, Diederichs K, Welte W, Boos W: Structural model of MalK, the ABC subunit of the maltose transporter of Escherichia coli: implications for mal gene regulation, inducer exclusion, and subunit assembly. J Biol Chem 2002;277:3708-3717.

-Boos W, Shuman H: Maltose/maltodextrin system of Escherichia coli: transport, metabolism, and regulation. Microbiol Mol Biol Rev 1998;62:204-229.

Button DK: Biochemical basis for whole-cell uptake kinetics: specific affinity, oligotrophic capacity, and the meaning of the Michaelis constant. Appl Environ Microbiol 1991;57: 2033-2038.

Dunning Hotopp JC, Lin M, Madupu R, Crabtree J, Angiuoli SV, Eisen J, Seshadri R, Ren Q, Wu M, Utterback TR, Smith S, Lewis M, Khouri H, Zhang C, Niu H, Lin Q, Ohashi N, Zhi N, Nelson W, Brinkac LM, Dodson RJ, Rosovitz MJ, Sundaram J, Daugherty SC, Davidsen T, Durkin AS, Gwinn M, Haft DH, Selengut JD, Sullivan SA, Zafar N, Zhou L, Benahmed F, Forberger H, Halpin R, Mulligan S, Robinson J, White O, Rikihisa Y, Tettelin H: Comparative genomics of emerging human Ehrlichiosis agents. PLoS Genet 2006;2:e21.

Elferink MG, Driessen AJ, Robillard GT: Functional reconstitution of the purified phosphoenolpyruvate-dependent mannitol-specific transport system of Escherichia coli in phospholipid vesicles: coupling between transport and phosphorylation. J Bacteriol 1990;172:7119-7125.

Giovannoni SJ, Tripp HJ, Givan S, Podar M, Vergin KL, Baptista D, Bibbs L, Eads J, Richardson TH, Noordewier M, Rappe MS, Short JM, Carrington JC, Mathur EJ: Genome streamlining in a cosmopolitan oceanic bacterium. Science 2005;309:1242-1245.
Janssen P, Goldovsky L, Kunin V, Darzentas N, Ouzounis CA: Genome coverage, literally speaking: the challenge of annotating 200 genomes with 4 million publications. EMBO Reports 2005;6:397-399.

Kowalchuk GA, Stephen JR: Ammonia-oxidizing bacteria: a model for molecular microbial ecology. Annu Rev Microbiol 2001;55 485-529.

Levesque M, Shasha D, Kim W, Surette MG, Benfey PN: Trait-to-gene: a computational method for predicting the function of uncharacterized genes. Curr Biol 2003;13:129133.

Linton KJ, Higgins CF: The Escherichia coli ATP-binding cassette (ABC) proteins. Mol Microbiol 1998;28:5-13.

-Marcotte EM, Xenarios I, van der Bliek AM, Eisenberg D: Localizing proteins in the cell from their phylogenetic profiles. Proc Natl Acad Sci USA 2000;97:12115-12120.

Moran MA, Buchan A, Gonzalez JM, Heidelberg JF, Whitman WB, Kiene RP, Henriksen JR, King GM, Belas R, Fuqua C, Brinkac L, Lewis M, Johri S, Weaver B, Pai G, Eisen JA, Rahe E, Sheldon WM, Ye W, Miller TR, Carlton J, Rasko DA, Paulsen IT, Ren Q, Daugherty SC, Deboy RT, Dodson RJ, Durkin AS, Madupu R, Nelson WC, Sullivan SA, Rosovitz MJ, Haft DH, Selengut J, Ward N: Genome sequence of Silicibacter pomeroyi reveals adaptations to the marine environment. Nature 2004;432:910-913.

Nelson KE, Clayton RA, Gill SR, Gwinn ML, Dodson RJ, Haft DH, Hickey EK, Peterson JD, Nelson WC, Ketchum KA, McDonald L, Utterback TR, Malek JA, Linher KD, Garrett MM, Stewart AM, Cotton MD, Pratt MS, Phillips CA, Richardson D, Heidelberg J, Sutton GG, Fleischmann RD, Eisen JA, White O, Salzberg SL, Smith HO, Venter JC, Fraser CM: Evidence for lateral gene transfer between Archaea and Bacteria from genome sequence of Thermotoga maritima. Nature 1999;399:323-329.

Newman MJ, Foster DL, Wilson TH, Kaback HR: Purification and reconstitution of functional lactose carrier from Escherichia coli. J Biol Chem 1981;256:11804-11808.

$>$ Ogata H, Audic S, Renesto-Audiffren P, Fournier PE, Barbe V, Samson D, Roux V, Cossart P, Weissenbach J, Claverie JM, Raoult D: Mechanisms of evolution in Rickettsia conorii and $R$. prowazekii. Science 2001;293: 2093-2098.

Palenik B, Brahamsha B, Larimer FW, Land M, Hauser L, Chain P, Lamerdin J, Regala W, Allen EE, McCarren J, Paulsen I, Dufresne A, Partensky F, Webb EA, Waterbury J: The genome of a motile marine Synechococcus. Nature 2003;424:1037-1042.
Palenik B, Ren Q, Dupont CL, Myers GS, Heidelberg JF, Badger JH, Madupu R, Nelson WC, Brinkac LM, Dodson RJ, Durkin AS, Daugherty SC, Sullivan SA, Khouri H, Mohamoud Y, Halpin R, Paulsen IT: Genome sequence of Synechococcus CC9311:Insights into adaptation to a coastal environment. Proc Natl Acad Sci USA 2006;103:13555-13559.

-Parkhill J, Sebaihia M, Preston A, Murphy LD, Thomson N, Harris DE, Holden MTG, Churcher CM, Bentley SD, Mungall KL, Cerdeno-Tarraga AM, Temple L, James K, Harris B, Quail MA, Achtman M, Atkin R, Baker S, Basham D, Bason N, Cherevach I, Chillingworth T, Collins M, Cronin A, Davis P, Doggett J, Feltwell T, Goble A, Hamlin N, Hauser H, Holroyd S, Jagels K, Leather S, Moule S, Norberczak H, O’Neil S, Ormond D, Price C, Rabbinowitsch E, Rutter S, Sanders M, Saunders D, Seeger K, Sharp S, Simmonds M, Skelton J, Squares R, Squares S, Stevens K, Unwin L, Whitehead S, Barrell BG, Maskell DJ: Comparative analysis of the genome sequences of Bordetella pertussis, Bordetella parapertussis and Bordetella bronchiseptica. Nat Genet 2003;35:32-40.

Paulsen IT, Nguyen L, Sliwinski MK, Rabus R, Saier MH Jr: Microbial genome analyses: comparative transport capabilities in eighteen prokaryotes. J Mol Biol 2000;301:75100.

-Paulsen IT, Seshadri R, Nelson KE, Eisen JA, Heidelberg JF, Read TD, Dodson RJ, Umayam L, Brinkac LM, Beanan MJ, Daugherty SC, Deboy RT, Durkin AS, Kolonay JF, Madupu R, Nelson WC, Ayodeji B, Kraul M, Shetty J, Malek J, Van Aken SE, Riedmuller S, Tettelin H, Gill SR, White O, Salzberg SL, Hoover DL, Lindler LE, Halling SM, Boyle SM, Fraser CM: The Brucella suis genome reveals fundamental similarities between animal and plant pathogens and symbionts. Proc Natl Acad Sci USA 2002;99:1314813153

Paulsen IT, Sliwinski MK, Saier MH Jr: Microbial genome analyses: global comparisons of transport capabilities based on phylogenies, bioenergetics and substrate specificities. J Mol Biol 1998;277:573-592.

Pellegrini M: Computational methods for protein function analysis. Curr Opin Chem Biol 2001;5:46-50.

Pellegrini M, Marcotte EM, Thompson MJ, Eisenberg D, Yeates TO: Assigning protein functions by comparative genome analysis: protein phylogenetic profiles. Proc Natl Acad Sci USA 1999;96:4285-4288.

Postma PW, Lengeler JW, Jacobson GR: Phosphoenolpyruvate:carbohydrate phosphotransferase systems of bacteria. Microbiol Rev 1993;57:543-594. 
Ren Q, Kang KH, Paulsen IT: TransportDB: a relational database of cellular membrane transport systems. Nucleic Acids Res 2004; 32:D284-D288.

Ren Q, Paulsen IT: Comparative analyses of fundamental differences in membrane transport capabilities in prokaryotes and eukaryotes. PLoS Comput Biol 2005;1:190-201.

Saier MH Jr: Classification of Transmembrane Transport Systems in Living Organisms. San Diego, Academic Press, 1999.

-Saier MH Jr: A functional-phylogenetic classification system for transmembrane solute transporters. Microbiol Mol Biol Rev 2000; 64:354-411.
Sweet G, Gandor C, Voegele R, Wittekindt N, Beuerle J, Truniger V, Lin EC, Boos W: Glycerol facilitator of Escherichia coli: cloning of $g l p F$ and identification of the $g l p F$ product. J Bacteriol 1990;172:424-430.

Tolner B, Ubbink-Kok T, Poolman B, Konings WN: Cation-selectivity of the L-glutamate transporters of Escherichia coli, Bacillus stearothermophilus and Bacillus caldotenax: dependence on the environment in which the proteins are expressed. Mol Microbiol 1995; 18:123-133.

Tucker AM, Winkler HH, Driskell LO, Wood DO: S-adenosylmethionine transport in Rickettsia prowazekii. J Bacteriol 2003;185: 3031-3035.

-Vandepoele K, Van de Peer Y: Exploring the plant transcriptome through phylogenetic profiling. Plant Physiol 2005;137:31-42.
Viitanen P, Newman MJ, Foster DL, Wilson TH, Kaback HR: Purification, reconstitution, and characterization of the lac permease of Escherichia coli. Methods Enzymol 1986; 125:429-452.

Wu M, Ren Q, Durkin AS, Daugherty SC, Brinkac LM, Dodson RJ, Madupu R, Sullivan SA, Kolonay JF, Haft DH, Nelson WC, Tallon LJ, Jones KM, Ulrich LE, Gonzalez JM, Zhulin IB, Robb FT, Eisen JA: Life in hot carbon monoxide: the complete genome sequence of Carboxydothermus hydrogenoformans Z2901. PLoS Genet 2005;1:e65.

Zientz E, Dandekar T, Gross R: Metabolic interdependence of obligate intracellular bacteria and their insect hosts. Microbiol Mol Biol Rev 2004;68:745-770. 